\title{
Geothermal Investigations in Permafrost Regions- The Duration of Temperature Monitoring after Wellbores Shut-In
}

\author{
Izzy M. Kutasov ${ }^{1}$, Lev V. Eppelbaum ${ }^{2}$ \\ ${ }^{1}$ Pajarito Enterprises, Santa Fe, New Mexico, USA \\ ${ }^{2}$ Department of Geophysics and Planetary Sciences, Raymond and Beverly Sackler \\ Faculty of Exact Sciences, Tel Aviv University, Ramat Aviv, Tel Aviv, Israel \\ Email: levap@post.tau.ac.il
}

Received August 4, 2012; revised September 26, 2012; accepted October 7, 2012

\begin{abstract}
The most important data on the thermal regime of the Earth's interior come from temperature measurements in deep boreholes. The drilling process greatly alters the temperature field of formations surrounding the wellbore. In permafrost regions, due to thawing of the formation surrounding the wellbore during drilling, representative data can be obtained only by repeated observations over a long period of time (up to 10 years). Usually a number of temperature logs (3 - 10) are taken after the well's shut-in. Significant expenses (manpower, transportation) are required to monitor the temperature regime of deep wells. In this paper we show that in most of the cases (when the time of refreezing formations is less than the shut-in time) two temperature logs are sufficient to predict formations temperatures during shut-in, to determine the geothermal gradients, and to evaluate the thickness of the permafrost zone. Thus the cost of monitoring the temperature regime of deep wells after shut-in can be drastically reduced. A simple method to process field data (for the well sections below and above the permafrost base) is presented. Temperature logs conducted in two wells were used to demonstrate utilization of this method.
\end{abstract}

Keywords: Permafrost; Formation Temperature; Shut-In Temperature; Deep Wells; Geothermal

\section{Introduction}

Temperature logs are commonly used to determine the permafrost temperature and thickness. When wells are drilled through permafrost, the natural temperature field of the formations (in the vicinity of the borehole) is disturbed and the frozen rocks thaw for some distances from the borehole axis. To determine the static temperature of the formation and permafrost thickness, one must wait for some period after completion of drilling before making geothermal measurements. This is socalled restoration time, after which the difference between the temperature of the formation and that of the fluid is less than the needed measurement accuracy. The presence of permafrost has a marked effect on the time required for the near-well-bore formations to recover their static temperatures. The duration of the refreezing of the layer thawed during drilling is very dependent on the natural temperature of formation; therefore, the rocks at the bottom of the permafrost refreeze very slowly. A lengthy restoration period of up to ten years or more is required to determine the temperature and thickness of permafrost with sufficient accuracy [1-6].
Earlier we suggested a "two point method" [7] which permits one to determine the permafrost thickness from short term (in comparison with the time required for temperature restoration) downhole temperature logs. The "two point method" of predicting the permafrost thickness is based on determining the geothermal gradient in a uniform layer below the permafrost zone. Only temperature measurements for two depths are needed to determine the geothermal gradient. The position of the permafrost base is predicted by the extrapolation of the static formation temperature-depth curve to $0^{\circ} \mathrm{C}$. It should be noted that here the permafrost base is defined as the $0^{\circ} \mathrm{C}$ isotherm. Precise temperature measurements $[2,3]$ taken in 15 deep wells located in Northern Canada (Arctic Islands and Mackenzie Delta) were used to verify the proposed method. Let us assume that at the moment of time $t=t_{e p}$ the phase transitions (water-ice) in formations at a selected depth are completed, i.e. the thermally disturbed formation has frozen. In this case at $t$ $>t_{e p}$ the cooling process is similar to that of temperature recovery in sections of the well below the permafrost base. It is well known [8] that the freezing of the wateroc 
curs in some temperature interval below $0^{\circ} \mathrm{C}$ (Figure 1). In practice, however, the moment of time $t=t_{e p}$ cannot be determined. Only conducting long-term repetitive temperature observations in deep wells can do this. Earlier we assumed that three shut-in temperatures $T_{s 1}, T_{s 2}$, and $T_{s 3}$ are measured at a given depth (Figure 1). For this case we proposed a method of predicting the formation temperatures [9].

A generalized formula to process field data (for the well sections below and above the permafrost base) was developed. Temperature logs conducted in five wells were used to apply this method [9].

It is demonstrated, by using field examples, that for deep boreholes several methods of predicting the permafrost temperature and its thickness should be applied. Low temperatures (from $-15^{\circ} \mathrm{C}$ to $-5^{\circ} \mathrm{C}$ ) are typical for upper sections of the well's lithological profile. In this case the refreezing period is short and the empirical formula [10] can be utilized to determine permafrost temperature and geothermal gradient) This is not the case for the lower sections of the wellbore where the surrounding formations are at high temperatures (from $-3^{\circ} \mathrm{C}$ to $-1^{\circ} \mathrm{C}$ ). Here freezing time is large and only "three point” method is used.

The objective of this paper is to show that in many cases (when the time of refreezing formations is less than the shut-in time) two temperature logs are sufficient to predict formations temperatures during shut-in, to determine the geothermal gradients, and to evaluate the thickness of the permafrost zone.

\section{Shut-In Temperatures-Permafrost Zone}

In 1959 in their classical paper Lachenbruch and Brewer [10] proposed an empirical formula (Equation (1)) to predict the wellbore temperatures during shut-in.

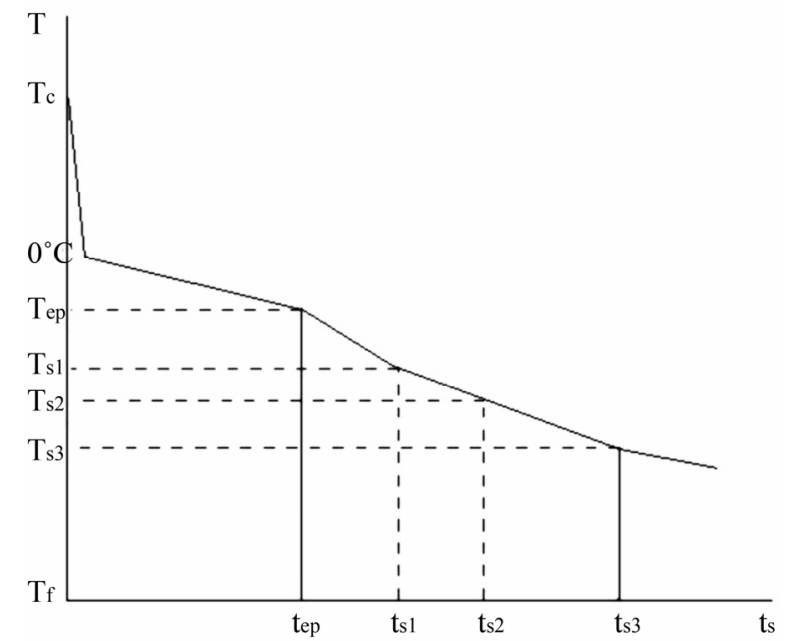

Figure 1. Shut-in temperatures at a given depth (above the permafrost base)-schematic curve.

$$
T_{s}=B \ln \left(1+\frac{t_{c}}{t_{s}}\right)+A
$$

where $A$ and $B$ are empirical coefficients determined from field measurements.

It is a reasonable assumption that the value of $t_{c}$ (the "disturbance" period) is a linear function of the depth $(h)$ :

$$
t_{c}=t_{t}\left(1-\frac{h}{h_{t}}\right)
$$

Equation (1) was successfully utilized to describe the measured shut-in temperature in the Well 3, Alaska, South Barrow. The well was drilled for 63 days to a total depth of $2900 \mathrm{ft}$. Temperature measurements to a depth of 595 feet were made during a period of six years after drilling. For the depth of $595 \mathrm{ft}$ the average value of $T_{f}$ is $6.568^{\circ} \mathrm{C}$ (9 temperature logs). The completion of freezing occurred at temperature of about $-0.6^{\circ} \mathrm{C}$ and duration of the complete freezeback is approximately 20 days (Figure 2).

US Geological Survey conducted extensive temperature measurements in Alaska (US Geological Survey “Site” File-Alaska, Internet [11]). We selected long term temperature surveys in three wells (Table 1) to find out if the proposed Equation (6) (see Section 3) can be used when only two temperature logs are available. In Table 2 the calculated values of $A$ and $B$ for two wells are presented. For the well Drew Point No.1 we used the values of $T_{s}$ measured in the first two temperature logs $\left(t_{s 1}=186\right.$ days $t_{s 2}=547$ days) to determine empirical coefficients $A$ and $B$. After this we calculated values of $T_{s}$ for the last temperature $\log \left(t_{s}=2339\right.$ days $)$.

Similarly, for the well East Simpson \#1 we used the values of $T_{s}$ measured in the first two temperature logs ( $t_{s 1}=155$ days, $t_{s 2}=520$ days $)$ to obtain values of $A$ and $B$. Values of $T_{s}$ determined for $t_{s}=1947$ days (the last temperature log) are also presented in Table 2. From For mula 1 follows that at $t_{s} \rightarrow \infty \quad T_{s} \rightarrow T_{f}=A$. Assuming

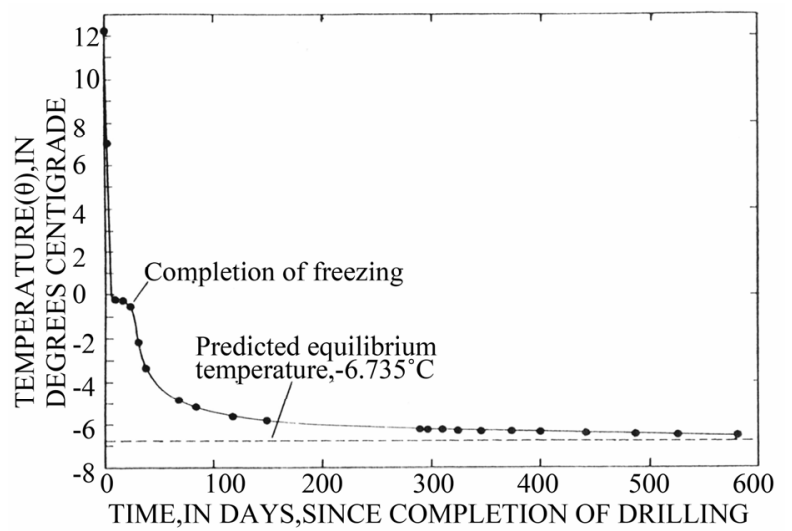

Figure 2. Cooling of South Barrow (Alaska) Well 3595-foot depth curve (after [10]). 
Table 1. Input data and location of three wells, Alaska, (US Geological Survey “Site” File-Alaska, Internet).

\begin{tabular}{|c|c|c|c|}
\hline Site code & PBF & DRP & ESN \\
\hline Site name & $\begin{array}{c}\text { Put River } \\
\text { N-1 }\end{array}$ & $\begin{array}{c}\text { Drew Point } \\
\text { No.1 }\end{array}$ & East Simpson \#1 \\
\hline Latitude & $70^{\circ} 19^{\prime} 07^{\prime \prime N}$ & $70^{\circ} 52^{\prime} 47.14^{\prime \prime} \mathrm{N}$ & $70^{\circ} 55^{\prime} 04.01 " \mathrm{~N}$ \\
\hline Longitude & $148^{\circ} 54^{\prime} 35^{\prime \prime} \mathrm{W}$ & $153^{\circ} 53^{\prime} 59.93 " \mathrm{~W}$ & $154^{\circ} 37^{\prime} 04.75^{\prime \prime W}$ \\
\hline Surface elevation, m & 8 & 5 & 4 \\
\hline Casing diameter, cm & 51 & 34 & 34 \\
\hline Hole depth, m & 763 & 640 & 600 \\
\hline Date of drill start & $02-09-70$ & $13-01-78$ & $19-02-79$ \\
\hline Drilling time, days & 44 & 60 & 51 \\
\hline Number of logs & 9 & 6 & 5 \\
\hline Shut-in time, days & $5-1071$ & $186-2339$ & $155-1947$ \\
\hline
\end{tabular}

Table 2. Calculated values of $A$ and $B$ for wells Drew Point \#1 and East Simpson \#1.

\begin{tabular}{|c|c|c|c|c|c|}
\hline$h, \mathrm{~m}$ & $T_{s 1},{ }^{\circ} \mathrm{C}$ & $T_{s 2},{ }^{\circ} \mathrm{C}$ & $A,{ }^{\circ} \mathrm{C}$ & $T_{s},{ }^{\circ} \mathrm{C}$ & $B,{ }^{\circ} \mathrm{C}$ \\
\hline \multicolumn{6}{|c|}{ Drew Point \#1 } \\
\hline \multicolumn{2}{|c|}{$t_{s 1}=186$ days } & \multicolumn{2}{|c|}{$t_{s 2}=547$ days } & \multicolumn{2}{|c|}{$t_{s}=2339$ days } \\
\hline 50.29 & -7.373 & -8.519 & -9.192 & -8.953 & 6.990 \\
\hline 70.10 & -6.925 & -8.142 & -8.854 & -8.574 & 7.639 \\
\hline 100.58 & -5.892 & -7.283 & -8.092 & -7.774 & 9.147 \\
\hline 120.40 & -5.309 & -6.638 & -7.408 & -7.140 & 9.022 \\
\hline 150.88 & -4.466 & -5.690 & -6.394 & -6.148 & 8.751 \\
\hline 170.69 & -3.951 & -5.076 & -5.721 & -5.518 & 8.336 \\
\hline 199.64 & -3.247 & -4.199 & -4.741 & -4.619 & 7.455 \\
\hline 219.46 & -2.698 & -3.639 & -4.173 & -4.032 & 7.672 \\
\hline \multicolumn{6}{|c|}{ East Simpson \#1 } \\
\hline \multicolumn{2}{|c|}{$t_{s 1}=155$ days } & \multicolumn{2}{|c|}{$t_{s 2}=520$ days } & \multicolumn{2}{|c|}{$t_{s}=1947$ days } \\
\hline 21.34 & -8.019 & -9.180 & -9.746 & -9.601 & 6.268 \\
\hline 42.67 & -7.501 & -8.817 & -9.456 & -9.245 & 7.332 \\
\hline 60.96 & -7.145 & -8.486 & -9.135 & -8.917 & 7.683 \\
\hline 79.25 & -6.699 & -7.999 & -8.626 & -8.437 & 7.669 \\
\hline 100.58 & -6.107 & -7.427 & -8.060 & -7.866 & 8.069 \\
\hline 124.97 & -5.538 & -6.736 & -7.308 & -7.155 & 7.644 \\
\hline 149.35 & -4.935 & -6.063 & -6.598 & -6.474 & 7.532 \\
\hline 173.74 & -4.487 & -5.499 & -5.977 & -5.905 & 7.092 \\
\hline 201.17 & -3.538 & -4.526 & -4.989 & -4.980 & 7.338 \\
\hline 225.55 & -2.775 & -3.963 & -4.517 & -4.308 & 9.328 \\
\hline 249.94 & -2.433 & -3.275 & -3.666 & -3.702 & 7.019 \\
\hline
\end{tabular}


that at values of $t_{s}=2339$ days and $t_{s}=1947$ days the values of $T_{s}$ are close to the undisturbed temperature of formations, we can see from Table 2 that values of $T_{s}$ and $A$ are in good agreement. In Tables $\mathbf{3}$ and $\mathbf{4}$ we compare the calculated and measured shut-in temperature. The agreement between the values $T_{e q}$ and $T_{s}$ is very good. US Geological Survey has obtained unique data for the well Put River N-1 (Table 5). Indeed, during two month of well's shut-in five temperature logs were taken. For the well Put River N-1 we used values of $t_{s 1}=34$ days and $t_{s 2}=66$ days to estimate the empirical coefficients $A$ and $B$.

In Table 6 we compare the calculated and measured shut-in temperatures for the well Put River N-1. In this case the difference between the calculated and measured temperatures is significant (Table 6). We can conclude that the shut-in times (34 and 66 days) are comparable with the formation freezeback period (Table 5). For this case we can use the suggested earlier a three-point method [9] for predicting the formation temperatures (Table 7). Here an additional temperature $\log \left(t_{s}=48\right.$ days) was used. From Table 7 follows that the agreement between calculated and measured temperatures is very good.

\section{Temperature Gradient and Estimation of the Permafrost Thickness}

In the permafrost areas the rate of heat flow at the frozen-unfrozen interface serves as the main criterion of the steadiness or non-steadiness of the thermal regime.

Let us assume that $q_{t}$ and $q_{f}$ are the heat flow density at the phase boundary in the unfrozen and frozen zone, respectively.

$$
\begin{gathered}
q_{f}=\lambda_{f} G_{f} \\
q_{u}=\lambda_{t} G_{t}
\end{gathered}
$$

where $\lambda$ is the thermal conductivity of geological formations.

It is clear that the condition $q_{f}=q_{u}$ corresponds to a steady regime, the condition $q_{f}>q_{u}$ corresponds to a regime of freezing and the condition $q_{f}<q_{u}$ corresponds to a thawing regime. In addition, the change in the heat flow density at the permafrost base (frozen-unfrozen interface) is also an indicator of the climate change in the past [1]. When interpreted with the heat conduction theory, these sources can provide important information of patterns of contemporary climate change. For example, precision measurements in oil wells in the Alaskan Arctic indicate a widespread warming $\left(2^{\circ} \mathrm{C}-4^{\circ} \mathrm{C}\right)$ at the permafrost surface during the 20th century [6]. Thus to estimate values of $q_{u}$ and $q_{f}$, it is necessary to determine the geothermal gradient and formation conductivity in the frozen and unfrozen sections of the wellbore. Unfortunately at present no methods are available for in-situ determination of formation conductivity. Samples of rocks are usually used to estimate formation thermal conductivity. Experimental studies show that $\lambda_{f}>\lambda_{u}$. For a given formation the $\lambda_{f}>\lambda_{u}$ ratio is mainly a function of total water content [12]. The duration of the refreezing of the layer thawed during drilling is very dependent on the natural temperature of formation; therefore, the rocks at the bottom of the permafrost refreeze very slowly. In practice the position of the permafrost base $\left(h_{p}\right)$ is estimated by extrapolation. Let us examine the restoration of the natural temperature field by the example of the Bakhynay borehole 1-R [1]. The borehole was drilled for 23 months (1956 - 1958) to a depth of 2824 m. Nine temperature logs were performed over a shut-in period of 10 years, but the difference between the temperature of formations and that in the borehole was still greater than the measurement accuracy $\left(0.03^{\circ} \mathrm{C}-0.05^{\circ} \mathrm{C}\right)$. After a shut-in period of 1.5 years the thickness of permafrost was estimated as $470 \mathrm{~m}$ instead of $650 \mathrm{~m}$. The restoration of the temperature regime was accompanied by formation of practically zero temperature gradient intervals (Figure 3). Therefore, if the shut-in time is insufficient, one may incorrectly attribute the zero temperature gradient intervals to some geological-geographical factors, an example of which in this case is the warming effect of the Lena River (the drilling site is the bank of the river). Below we present several examples of determination of the temperature gradients and evaluation of the permafrost thickness. For each section of the well we used a linear regression program to calculate the coefficients in the following equation

$$
T_{s}=a+g h
$$

As can be seen for the section $21.34-249.94 \mathrm{~m}$ at $t_{s}=$ 520 days (Table 8) practically $g=G\left(0.0267^{\circ} \mathrm{C} / \mathrm{m}\right)$. Similarly, for section $451.10-600.46 \mathrm{~m}$ at $t_{s}=520$ days the values $g$ and $G$ are very close $(0.0408$ and $\left.0.0415^{\circ} \mathrm{C} / \mathrm{m}\right)$. Finally, the position of the permafrost base $\left(h_{p}\right)$ is estimated by extrapolation by using Equation (3) for $T_{s}=0^{\circ} \mathrm{C}$.

Therefore:

$$
0=a+g h, h_{p}=-\frac{a}{g}
$$

As can be seen the values of $h_{p}$ calculated for both sections of the well are in a good agreement (Table 8). In Table 9 we present an example of data processing for two wells. As can be seen shut-in times of 155 days and 186 days do not enable to estimate the permafrost thickness with a sufficient accuracy. Earlier we developed "two temperature logs method" for determination the undisturbed formation temperatures.

The working formulas are [13, p. 171]:

$$
T_{f}=T_{s 2}-\gamma\left(T_{s 1}-T_{s 2}\right)
$$


Table 3. Comparison of measured and observed shut-in temperatures, well East Simpson \#1.

\begin{tabular}{|c|c|c|c|c|c|c|c|c|}
\hline$h, m$ & $A,{ }^{\circ} \mathrm{C}$ & $B,{ }^{\circ} \mathrm{C}$ & $T_{e q},{ }^{\circ} \mathrm{C}$ & $T_{s},{ }^{\circ} \mathrm{C}$ & $T_{e q},{ }^{\circ} \mathrm{C}$ & $T_{s},{ }^{\circ} \mathrm{C}$ & $T_{e q},{ }^{\circ} \mathrm{C}$ & $T_{s},{ }^{\circ} \mathrm{C}$ \\
\hline & & & \multicolumn{2}{|c|}{ at $t_{s}=865$ days } & \multicolumn{2}{|c|}{ at $t_{s}=1608$ days } & \multicolumn{2}{|c|}{ at $t_{s}=1947$ days } \\
\hline 21.34 & -9.746 & 6.268 & -9.399 & 9.344 & 9.557 & & -9.590 & -9.601 \\
\hline 42.67 & -9.456 & 7.332 & -9.065 & -9.060 & -9.243 & -9.222 & -9.280 & -9.245 \\
\hline 60.96 & -9.135 & 7.683 & -8.738 & -8.742 & -8.919 & -8.903 & -8.956 & -8.917 \\
\hline 79.25 & -8.626 & 7.669 & -8.243 & -8.274 & -8.418 & -8.440 & -8.454 & -8.437 \\
\hline 100.58 & -8.060 & 8.069 & -7.673 & -7.692 & -7.850 & & -7.886 & -7.866 \\
\hline 124.97 & -7.308 & 7.644 & -6.959 & -6.987 & -7.118 & & -7.151 & -7.155 \\
\hline 149.35 & -6.598 & 7.532 & -6.272 & -6.303 & -6.421 & & -6.451 & -6.474 \\
\hline 173.74 & -5.977 & 7.092 & -5.686 & -5.734 & -5.819 & & -5.846 & -5.905 \\
\hline 201.17 & -4.989 & 7.338 & -4.707 & -4.799 & -4.836 & -4.940 & -4.862 & -4.980 \\
\hline 225.55 & -4.517 & 9.328 & -4.180 & -4.137 & -4.334 & -4.285 & -4.366 & -4.308 \\
\hline 249.94 & -3.666 & 7.019 & -3.429 & -3.524 & -3.537 & -3.684 & -3.560 & -3.702 \\
\hline 274.32 & -3.066 & 4.944 & -2.910 & -3.023 & -2.982 & -3.126 & -2.996 & -3.161 \\
\hline 301.75 & -2.113 & 5.660 & -1.950 & -2.085 & -2.024 & & -2.040 & -2.247 \\
\hline
\end{tabular}

Table 4. Comparison of measured and observed shut-in temperatures, well Drew Point \#1.

\begin{tabular}{|c|c|c|c|c|c|c|c|c|}
\hline$h, \mathrm{~m}$ & $A,{ }^{\circ} \mathrm{C}$ & $B,{ }^{\circ} \mathrm{C}$ & $T_{e q},{ }^{\circ} \mathrm{C}$ & $T_{s},{ }^{\circ} \mathrm{C}$ & $T_{e q},{ }^{\circ} \mathrm{C}$ & $T_{s},{ }^{\circ} \mathrm{C}$ & $T_{e q},{ }^{\circ} \mathrm{C}$ & $T_{s},{ }^{\circ} \mathrm{C}$ \\
\hline & & & \multicolumn{2}{|c|}{ at $t_{s}=907$ days } & \multicolumn{2}{|c|}{ at $t_{s}=1259$ days } & \multicolumn{2}{|c|}{ at $t_{s}=2339$ days } \\
\hline 50.29 & -9.192 & 6.990 & -8.778 & -8.726 & -8.892 & -8.736 & -9.029 & -8.953 \\
\hline 70.10 & -8.854 & 7.639 & -8.417 & -8.355 & -8.537 & -8.292 & -8.681 & -8.574 \\
\hline 100.58 & -8.092 & 9.147 & -7.596 & -7.470 & -7.732 & -7.607 & -7.896 & -7.774 \\
\hline 120.40 & -7.408 & 9.022 & -6.936 & -6.852 & -7.066 & -6.953 & -7.222 & -7.140 \\
\hline 150.88 & -6.394 & 8.751 & -5.962 & -5.856 & -6.081 & -5.961 & -6.224 & -6.148 \\
\hline 170.69 & -5.721 & 8.336 & -5.326 & -5.233 & -5.435 & -5.335 & -5.566 & -5.518 \\
\hline 199.64 & -4.741 & 7.455 & -4.409 & -4.342 & -4.500 & -4.441 & -4.611 & -4.619 \\
\hline 219.46 & -4.173 & 7.672 & -3.847 & -3.760 & -3.936 & -3.860 & -4.045 & -4.032 \\
\hline 243.84 & -3.336 & 5.148 & -3.129 & -3.043 & -3.186 & -2.991 & -3.255 & -3.304 \\
\hline
\end{tabular}


Table 5. Measured shut-in temperatures, well Put River N-1.

\begin{tabular}{|c|c|c|c|c|c|c|}
\hline \multirow{2}{*}{$h, \mathrm{~m}$} & \multicolumn{6}{|c|}{ Shut-in time, days } \\
\hline & 5 & 22 & 34 & 48 & 66 & 1071 \\
\hline 30.48 & -0.400 & -2.686 & -4.793 & -6.252 & -7.040 & -9.167 \\
\hline 45.72 & -0.300 & -2.093 & -4.507 & -6.012 & -6.910 & -9.052 \\
\hline 60.96 & -0.250 & -2.941 & -4.911 & -6.148 & -6.950 & -8.957 \\
\hline 91.44 & -0.300 & -1.633 & -4.101 & -5.646 & -6.590 & -8.771 \\
\hline 121.92 & -0.210 & -0.882 & -2.565 & -4.781 & -6.060 & -8.520 \\
\hline 152.40 & -0.030 & -0.976 & -1.852 & -3.173 & -4.760 & -8.124 \\
\hline 182.88 & 0.020 & -0.757 & -1.217 & -2.506 & & -7.619 \\
\hline 213.36 & 0.200 & -0.490 & -0.805 & -1.528 & & -7.144 \\
\hline 243.84 & 0.380 & -0.433 & -0.608 & -0.950 & -2.660 & -6.602 \\
\hline 274.32 & 0.640 & -0.418 & -0.555 & -0.823 & & -6.029 \\
\hline 304.80 & 0.740 & -0.379 & -0.506 & -0.682 & -1.150 & -5.462 \\
\hline 335.28 & 0.910 & -0.325 & -0.451 & -0.577 & & -4.935 \\
\hline 365.76 & 1.040 & -0.322 & -0.452 & -0.579 & -0.800 & -4.454 \\
\hline 396.24 & 1.230 & -0.354 & -0.505 & -0.644 & -0.860 & -4.039 \\
\hline 426.72 & 1.220 & -0.280 & -0.415 & -0.517 & -0.630 & -3.453 \\
\hline 457.20 & 1.890 & -0.326 & -0.395 & -0.497 & & -2.961 \\
\hline 487.68 & 1.480 & -0.305 & -0.398 & -0.476 & & -2.493 \\
\hline 518.16 & 1.520 & -0.264 & -0.309 & -0.389 & & -2.006 \\
\hline 548.64 & 1.880 & -0.171 & -0.316 & -0.382 & & -1.418 \\
\hline 579.12 & 2.540 & -0.010 & -0.236 & -0.309 & -360 & -0.778 \\
\hline 609.60 & 2.600 & 3.491 & 1.918 & 1.212 & 0.710 & -0.195 \\
\hline 640.08 & 6.830 & 5.275 & 4.047 & 3.254 & 2.640 & 0.761 \\
\hline 670.56 & 9.350 & 5.948 & 4.749 & 4.002 & & 1.664 \\
\hline 701.04 & 9.910 & 7.251 & 6.022 & 5.256 & 4.650 & 2.885 \\
\hline
\end{tabular}

Table 6. Comparison of measured and observed shut-in temperatures, well Put River N-1.

\begin{tabular}{|c|c|c|c|c|c|c|c|c|}
\hline$h, \mathrm{~m}$ & $A,{ }^{\circ} \mathrm{C}$ & $B,{ }^{\circ} \mathrm{C}$ & $T_{e q},{ }^{\circ} \mathrm{C}$ & $T_{s},{ }^{\circ} \mathrm{C}$ & $T_{e q},{ }^{\circ} \mathrm{C}$ & $T_{s},{ }^{\circ} \mathrm{C}$ & $T_{e q},{ }^{\circ} \mathrm{C}$ & $T_{s},{ }^{\circ} \mathrm{C}$ \\
\hline & & & \multicolumn{2}{|c|}{ at $t_{s}=117$ days } & \multicolumn{2}{|c|}{ at $t_{s}=163$ days } & \multicolumn{2}{|c|}{ at $t_{s}=1071$ days } \\
\hline 30.48 & -10.728 & 6.703 & -8.407 & -7.970 & -8.985 & -8.716 & -10.432 & -9.167 \\
\hline 45.72 & -10.824 & 7.265 & -8.366 & -7.900 & -8.979 & -8.428 & -10.511 & -9.052 \\
\hline 60.96 & -10.246 & 6.251 & -8.180 & -7.860 & -8.698 & -8.263 & -9.984 & -8.957 \\
\hline 91.44 & -9.262 & 5.303 & -7.595 & -7.620 & -8.015 & -7.965 & -9.052 & -8.771 \\
\hline 121.92 & -10.486 & 8.121 & -8.065 & -7.250 & -8.678 & -7.624 & -10.184 & -8.520 \\
\hline 152.40 & -9.235 & 9.832 & -6.467 & -6.510 & -7.172 & -7.026 & -8.892 & -8.124 \\
\hline
\end{tabular}


Table 7. Observed $\left(T^{*}\right)$ and calculated $(T)$ shut-in temperatures $\left({ }^{\circ} \mathrm{C}\right)$ at three depths of the Put River $\mathrm{N}-1$ well, Alaska; $t_{s 1}=34$, $t_{\mathrm{s} 2}=48$, and $t_{\mathrm{s} 3}=66$ days (after [9]).

\begin{tabular}{cccccccc}
\hline$t_{s}$, days & \multicolumn{3}{c}{$45.72 \mathrm{~m}$} & \multicolumn{2}{c}{$60.96 \mathrm{~m}$} & \multicolumn{2}{c}{$91.44 \mathrm{~m}$} \\
\hline & $T$ & $T^{*}$ & $\mathrm{~T}$ & $T^{*}$ & $T$ & $T^{*}$ \\
91 & -7.546 & -7.511 & -7.525 & -7.497 & -7.258 & -7.227 \\
117 & -7.921 & -7.900 & -7.867 & -7.860 & -7.651 & -7.620 \\
163 & -8.294 & -8.428 & -8.207 & -8.263 & -8.040 & -7.965 \\
1071 & -9.098 & -9.052 & -8.946 & -8.957 & -8.875 & -8.771 \\
\hline
\end{tabular}

Table 8. The estimated values of permafrost thickness for two sections, East Simpson \#1.

\begin{tabular}{|c|c|c|c|}
\hline$t_{s}$, days & $G,{ }^{\circ} \mathrm{C} / \mathrm{m}$ & $B,{ }^{\circ} \mathrm{C}$ & $h_{z}, \mathrm{~m}$ \\
\hline \multicolumn{4}{|c|}{ Section 21.34 - $249.94 \mathrm{~m}$} \\
\hline 155 & 0.02501 & -8.6303 & 345.1 \\
\hline 520 & 0.02660 & -9.9999 & 375.9 \\
\hline 865 & 0.02658 & -10.236 & 385.1 \\
\hline 1608 & 0.02750 & -10.519 & 382.1 \\
\hline 1947 & 0.02673 & -10.437 & 390.5 \\
\hline \multicolumn{4}{|c|}{ Section 451.10 - $600.46 \mathrm{~m}$} \\
\hline 155 & 0.04008 & -13.674 & 341.2 \\
\hline 520 & 0.04078 & -14.492 & 355.4 \\
\hline 865 & 0.04109 & -15.035 & 365.9 \\
\hline 1608 & 0.04105 & -15.139 & 368.8 \\
\hline 1947 & 0.04150 & -15.432 & 371.8 \\
\hline
\end{tabular}

Table 9. An example of data processing for two wells.

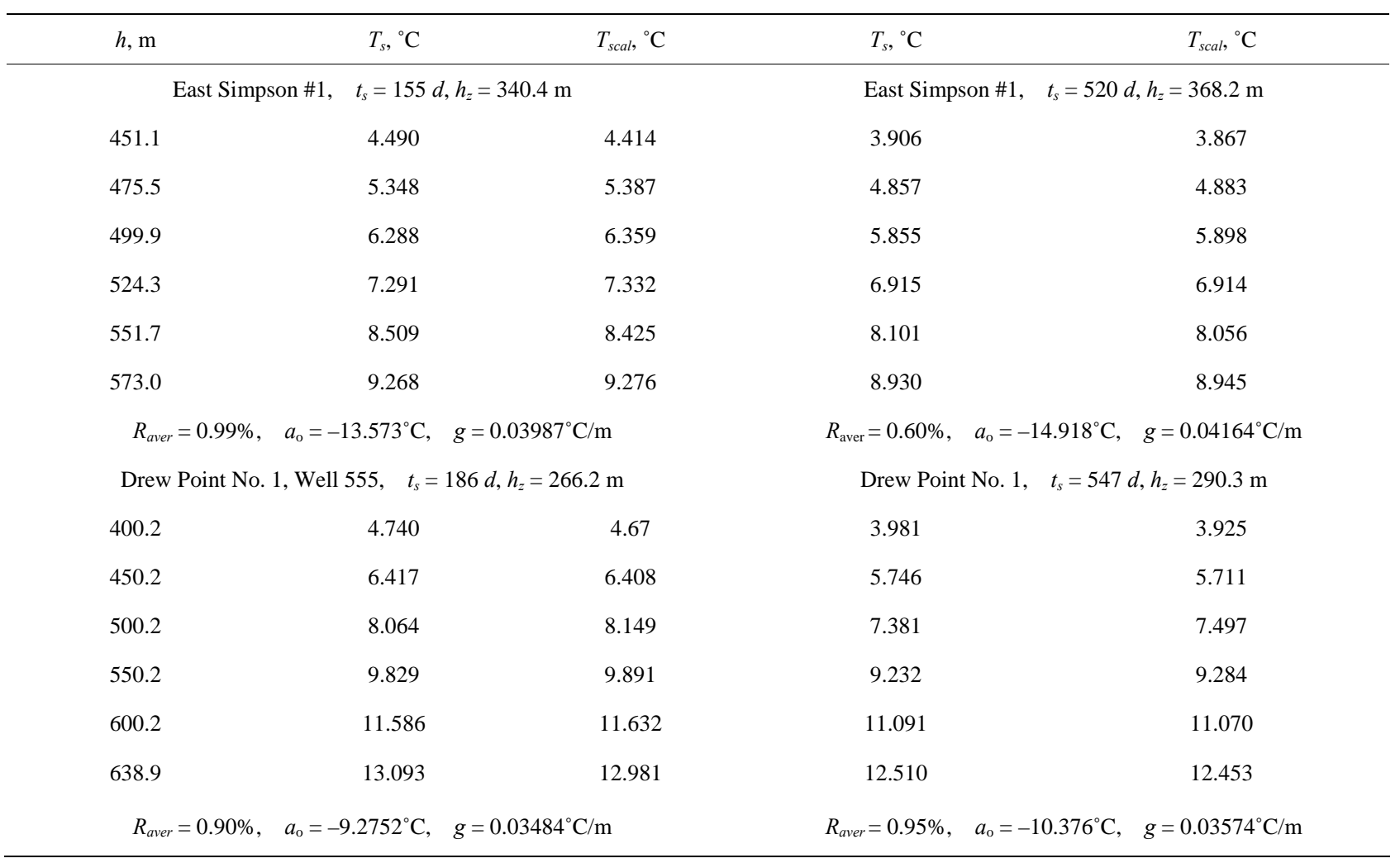




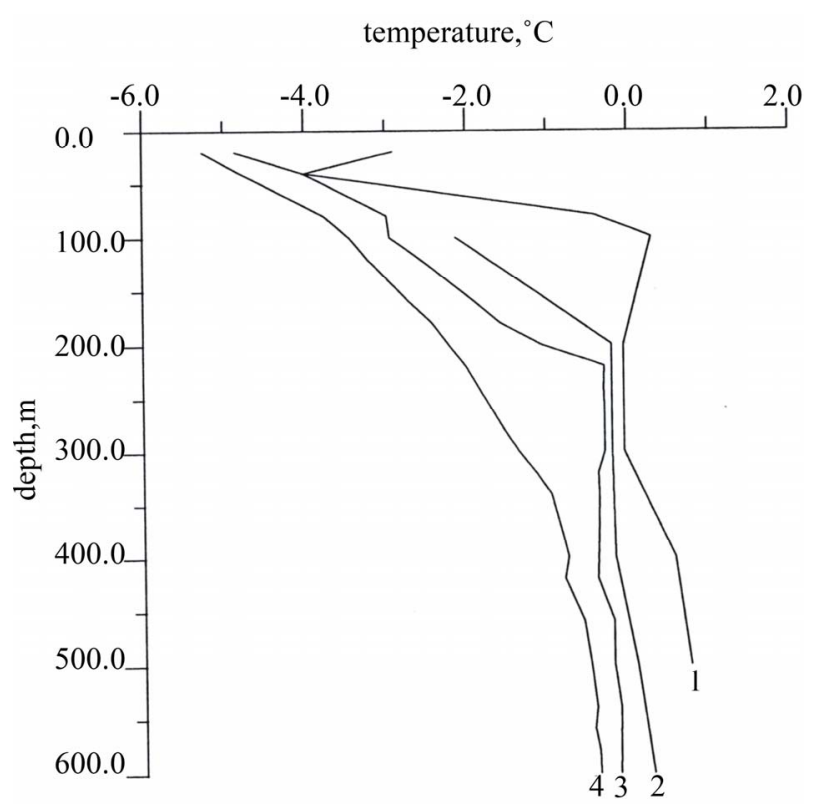

Figure 3. Restoration of temperature profile in the Bakhynay borehole 1-R (after [1]). Temperature surveys 1, 2, 3, and 4 were conducted at shut-in times of $0.4,1.5,3.4$ and 10.4 years, respectively.

where

$$
\begin{gathered}
\gamma=\frac{\operatorname{Ei}\left(-D / n_{2}\right)+\ln n_{2}-D_{1}}{\operatorname{Ei}\left(-D / n_{2}\right)-E i\left(-D / n_{1}\right)+\ln \frac{n_{2}}{n_{1}}} \\
n_{1}=\frac{t_{s 1}}{t_{c}}, n_{2}=\frac{t_{s 2}}{t_{c}} \\
D=1.1925, D_{1}=0.7532
\end{gathered}
$$

In Table 10 we present results of estimation of the formation temperature for two wells. And, finally, we use a linear regression program to determine the geothermal gradient (Table 11).

$$
T f=a+G h
$$

The position of the permafrost base $\left(h_{p}\right)$ is estimated by extrapolation

$$
0=a+G h_{p}, h p=-\frac{a}{G}
$$

Comparing the results of calculation $h_{p}$ (Table 9 at $t_{s}=$ 520 days and $t_{s}=547$ days) with that (Table 11) we can see the agreement between calculated values of $h_{p}$ is good.

\section{Onset of Formations Freezeback}

To plan the schedule of conducting temperature logs is important approximately to estimate the onset of the formations freezeback. Earlier we introduced term "safety period"- the length of the shut-in period during which water-base mud remains free from freezing in permafrost areas [14]. From physical considerations it is clear that the "safety period" $\left(t_{s p}\right)$ can be determine from the condition $T_{s}\left(t_{s p}\right)=0^{\circ} \mathrm{C}$ (Figure 2). Thus, the time $t_{s}=$ $t_{s p}$ can be considered as the onset of the formations freezeback. The magnitude of the "safety period" depends mainly on the duration of the thermal disturbance (drilling time) and on the static temperature of permafrost. Precise temperature measurements (61 logs) conducted by the Geothermal Service of Canada in 32 deep shut-in wells in Northern Canada [2-5] were used to estimate the values of $t_{s p}$ [14]. The total drilling time $\left(t_{t}\right)$ for these wells ranged from 4 to 404 days, the total vertical depth $\left(h_{t}\right)$ ranged from $1356 \mathrm{~m}$ to $4704 \mathrm{~m}$ ), and the depth of permafrost $\left(h_{p}\right)$ ranged from $74 \mathrm{~m}$ to $726 \mathrm{~m}$. The range of formations temperatures was $-0.5^{\circ} \mathrm{C}>T_{f}>$ $-4.6^{\circ} \mathrm{C}$.

We have found that the duration of the "safety period" $t_{s p}$ for a given depth can be approximated with sufficient accuracy as a function of two independent variables: time of thermal disturbance at the given depth (drilling time) and permafrost static temperature $\left(T_{f}\right)$. A regression analysis computer program was used to process field data. It was revealed that the following empirical formula could be used to estimate the safety shut-in period:

$$
t_{s p}=6.12 t_{c}^{0.817}\left(-T_{f}\right)^{-1.5}
$$

where $t_{c}$ is the thermal disturbance time (in days) at a given depth and temperature is inoc.

The value $t_{d}$ is: $t_{d}=t_{t}-t_{h}$, where $t_{h}$ is the period of time needed to reach the given depth. The values of $t_{h}$ can be determined from drilling records. The value $t_{d}$ can be also estimated from Equation (2). Please note that in our paper [14] a safety factor of 2 was introduced in Equation (7). When planning to conduct a temperature $\log$ the condition $t_{s}>t_{s p}$ should be satisfied. We conducted calculations of $t_{s p}$ for the section 335.3 - 548.6 m, well Put River N-1 (Table 12). From Table 12 follows that for the temperature logs with $t_{s}=5$ days and $t_{s}=22$ days the condition $t_{s}>>t_{s p}$ is not satisfied. As a result these temperature logs cannot be used for determination formation temperatures and estimation of the permafrost thickness. It should be remembered that in Equation (7), time is in days and temperature inoc.

\section{Conclusion}

It is shown that for large shut-in times the empirical Lachenbruch-Brewer formula can be used with good accuracy to estimate the shut-in temperatures. Only two temperature logs are needed to calculate the coefficients in the Lachenbruch-Brewer formula. Thus two temperature logs enable to predict formations temperatures, to determine the geothermal gradients, and to evaluate the thickness of 
Table 9. An example of data processing for two wells.

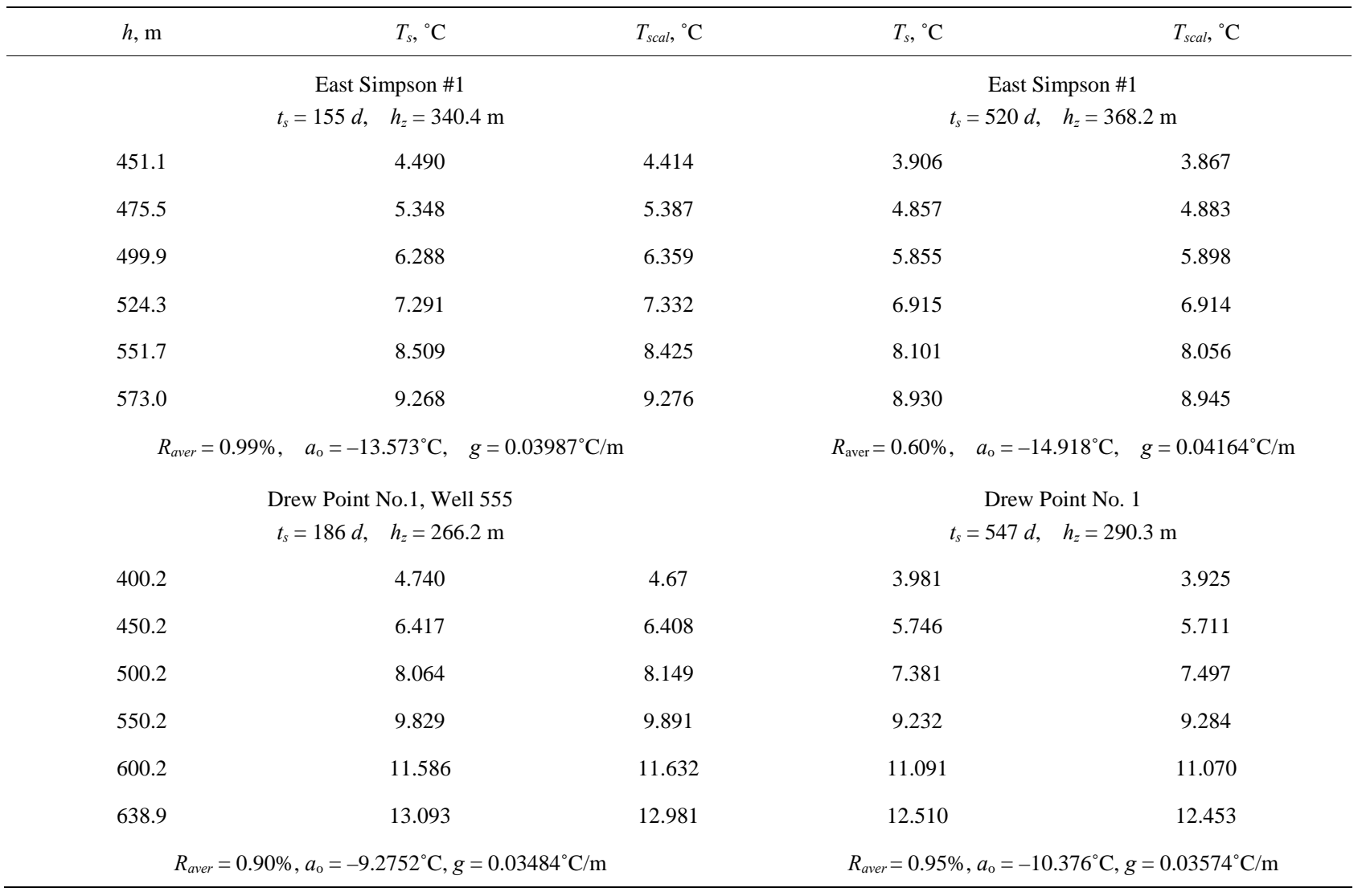

Table 10. Calculated formation temperatures by “two temperature logs method".

\begin{tabular}{|c|c|c|c|}
\hline$h, \mathrm{~m}$ & $T_{s 1},{ }^{\circ} \mathrm{C}$ & $T_{s 2},{ }^{\circ} \mathrm{C}$ & $T_{f},{ }^{\circ} \mathrm{C}$ \\
\hline \multicolumn{4}{|c|}{ Well East Simpson \#1 } \\
\hline \multicolumn{2}{|c|}{$t_{s 1}=155$ days } & \multicolumn{2}{|c|}{$t_{s 2}=520$ days } \\
\hline 451.10 & 4.490 & 3.906 & 3.653 \\
\hline 475.49 & 5.348 & 4.857 & 4.645 \\
\hline 499.87 & 6.288 & 5.855 & 5.669 \\
\hline 524.26 & 7.291 & 6.915 & 6.754 \\
\hline 551.69 & 8.509 & 8.101 & 7.928 \\
\hline 573.03 & 9.268 & 8.930 & 8.788 \\
\hline \multicolumn{4}{|c|}{ Drew Point No.1 } \\
\hline \multicolumn{2}{|c|}{$t_{s 1}=186$ days } & \multicolumn{2}{|c|}{$t_{s 2}=547$ days } \\
\hline 400.20 & 4.740 & 3.981 & 3.576 \\
\hline 450.19 & 6.417 & 5.746 & 5.391 \\
\hline 500.16 & 8.064 & 7.381 & 7.023 \\
\hline 550.17 & 9.829 & 9.232 & 8.921 \\
\hline 600.15 & 11.586 & 11.091 & 10.837 \\
\hline 638.86 & 13.093 & 12.510 & 12.303 \\
\hline
\end{tabular}


Table 11. Determination of the geothermal gradient, $R=\frac{T_{f c a l}-T_{f}}{T_{f}} \times 100 \%$.

\begin{tabular}{|c|c|c|c|}
\hline$h, \mathrm{~m}$ & $T_{f},{ }^{\circ} \mathrm{C}$ & $T_{\text {fcal }},{ }^{\circ} \mathrm{C}$ & $R, \%$ \\
\hline \multicolumn{4}{|c|}{ Well East Simpson \#1 } \\
\hline \multicolumn{4}{|c|}{$R_{\text {aver }}=0.43 \%, \quad h_{z}=365.6 \mathrm{~m}$} \\
\hline \multicolumn{4}{|c|}{$T_{f}=a_{\mathrm{o}}+G h$} \\
\hline \multicolumn{4}{|c|}{$G=0.04245^{\circ} \mathrm{C} / \mathrm{m}, \quad a_{0}=-15.518^{\circ} \mathrm{C}$} \\
\hline 451.10 & 3.6530 & 3.6301 & 0.63 \\
\hline 475.49 & 4.6450 & 4.6653 & -0.44 \\
\hline 499.87 & 5.6690 & 5.7002 & -0.55 \\
\hline 524.26 & 6.7540 & 6.7355 & 0.27 \\
\hline 551.69 & 7.9280 & 7.8998 & 0.36 \\
\hline 573.03 & 8.7880 & 8.8056 & -0.20 \\
\hline \multirow{3}{*}{\multicolumn{4}{|c|}{$\begin{array}{l}\text { Drew Point No. } 1 \\
R_{\text {aver }}=1.23 \%, \quad h_{z}=304.0 \mathrm{~m} \\
G=0.03652^{\circ} \mathrm{C} / \mathrm{m}, \quad a_{o}=-11.103^{\circ} \mathrm{C}\end{array}$}} \\
\hline & & & \\
\hline & & & \\
\hline 400.20 & 3.5760 & 3.5131 & 1.76 \\
\hline 450.19 & 5.3910 & 5.3388 & 0.97 \\
\hline 500.16 & 7.0230 & 7.1638 & -2.00 \\
\hline 550.17 & 8.9210 & 8.9903 & -0.78 \\
\hline 600.15 & 10.8370 & 10.8156 & 0.20 \\
\hline 638.86 & 12.3030 & 12.2293 & 0.60 \\
\hline
\end{tabular}

Table 12. The values of $t_{s p}$ for the section 335.3 - 548.6 m, well Put River N-1.

\begin{tabular}{|c|c|c|c|c|c|}
\hline$h, \mathrm{~m}$ & $t_{d}$, days & $T_{f},{ }^{\circ} \mathrm{C}$ & $t_{s p}$, days & $\begin{array}{c}t_{s}=5 \text { days } \\
T_{s},{ }^{\circ} \mathrm{C}\end{array}$ & $\begin{array}{c}t_{s}=22 \text { days } \\
T_{s},{ }^{\circ} \mathrm{C}\end{array}$ \\
\hline 335.3 & 24.7 & -4.93 & 7.7 & .910 & -.325 \\
\hline 365.8 & 22.9 & -4.45 & 8.4 & 1.040 & -.322 \\
\hline 396.2 & 21.1 & -4.04 & 9.1 & 1.230 & -.354 \\
\hline 426.7 & 19.4 & -3.45 & 10.8 & 1.220 & -.280 \\
\hline 457.2 & 17.6 & -2.96 & 12.5 & 1.890 & -.326 \\
\hline 487.7 & 15.9 & -2.49 & 14.9 & 1.480 & -.305 \\
\hline 518.2 & 14.1 & -2.01 & 18.7 & 1.520 & -.264 \\
\hline 548.6 & 12.4 & -1.42 & 28.3 & 1.880 & -.171 \\
\hline
\end{tabular}


the permafrost zone. As a result the cost of monitoring the temperature regime of deep wells after shut-in can be drastically reduced. For short shut times (comparable with the time of complete freezeback) we suggest to utilize the "Three point method" [9]. The approximate evaluation of the onset of formations freezeback will assist in planning the schedule of conducting temperature logs.

\section{Acknowledgements}

The authors would like to thank an anonymous reviewer, who thoroughly reviewed the manuscript, and his critical comments and valuable suggestions were helpful in preparing this paper.

\section{REFERENCES}

[1] P. I. Melnikov, V. T. Balobayev, I. M. Kutasov and V. N. Devyatkin, "Geothermal Studies in Central Yakutia," International Geology Review, Vol. 16, No. 5, 1974, pp. 565-568. doi:10.1080/00206817409471838

[2] A. E. Taylor and A. S. Judge, "Canadian Geothermal Data Collection-Northern Wells 1976-1977,” Geothermal Series, 10, Earth Physics Branch, Energy, Mines and Resources, Ottawa, 1977.

[3] A. S. Judge, A. E. Taylor and M. Burgess, "Canadian Geothermal Data Collection-Northern Wells 1977-1978," Geothermal Series, 11, Earth Physics Branch, Energy, Mines and Resources, Ottawa, 1979.

[4] A. S. Judge, A. E. Taylor, M. Burgess and V. S. Allen, "Canadian Geothermal Data Collection-Northern Wells 1978-1980,” Geothermal Series, 12, Earth Physics Branch, Energy, Mines and Resources, Ottawa, 1981.

[5] A. E. Taylor, M. Burgess, A. S. Judge and V. S. Allen,
"Canadian Geothermal Data Collection-Northern Wells 1981,” Geothermal Series, 13, Earth Physics Branch, Energy, Mines and Resources, Ottawa, 1982.

[6] A. H. Lachenbruch, T. T. Cladouhos and R. W. Saltus, "Permafrost Temperature and the Changing Climate," Proceedings of the Fifth International Conference on Permafrost, Trondheim, 2-5 August 1988, pp. 9-17.

[7] I. M. Kutasov, "Prediction of Permafrost Thickness by the 'Two Point' Method," Proceedings of the Fifth International Conference on Permafrost, Trondheim, 2-5 August 1988, pp. 965-970.

[8] N. A. Tsytovich, "The Mechanics of Frozen Ground," Scripta Book Comp., Washington DC, 1975.

[9] I. M. Kutasov and L. V. Eppelbaum, "Prediction of Formation Temperatures in Permafrost Regions from Temperature Logs in Deep Wells-Field Cases,” Permafrost and Periglacial Processes, Vol. 14, No. 3, 2003, pp. 247258. doi:10.1002/ppp.457

[10] A. H. Lachenbruch and M. C. Brewer, "Dissipation of the Temperature Effect of Drilling a Well in Arctic Alaska," US Geological Survey Bulletin, Vol. 1083-C, 1959, pp. 74-109.

[11] “Boreholes Locations and Permafrost Depths,” Alaska, from US Geological Survey, 1998. http://nsidc.org/data/docs/fgdc/ggd223_boreholes_alaska

[12] V. T. Balobayev, "Geothermics of the Frozen Zone of the Lithosphere of the Northern Asia,” Nauka, Novosibirsk, 1991.

[13] I. M. Kutasov, "Applied Geothermics for Petroleum Engineers,” In: Development in Petroleum Science, Elsevier, 1999.

[14] I. M. Kutasov and D. G. Strickland, "Allowable Shut-In Is Estimated for Wells in Permafrost," Oil and Gas Journal, 1988, pp. 55-60, OSTI ID: 6765096. 


\section{Nomenclature}

$A, B$-Empirical coefficients (Equation (1)); $a$-Parameter (Equations (3) and (6));

$G$-Geothermal gradient;

$g$-Temperature gradient;

$h_{t}$-Total well depth;

$h$-Depth;

$h_{p}$-Depth to base of ice-bounded permafrost;

$T_{e q}$-Shut-in temperature predicted by LachenbruchBrewer formula;

$T_{f}$ —Formation temperature;

$T_{s}$-Shut-in temperature;

t-Time;
$t_{c}$-Time of "thermal disturbance" at a given depth;

$t_{t}$-Otal drilling time;

$t_{s}$-Shut-in time;

$t_{e p}$ - Time of the thawed formation refreezing;

$t_{s p}$-Onset of the formation freezeback.

\section{Greek Symbols}

$\lambda$-Thermal conductivity of formations.

\section{Subscripts}

$u$-Unfrozen;

$f$-Frozen. 